\title{
Epistemological Disjunctivism and Introspective Indiscriminability
}

\author{
Chris Ranalli ${ }^{1}$
}

Received: 31 October 2017 / Revised: 14 March 2018 / Accepted: 29 March 2018 / Published online: 16 April 2018

(C) The Author(s) 2018

\begin{abstract}
According to Duncan Pritchard's Philosophical Issues, 21(1), 434-455, (2011, 2012, 2015)version of epistemological disjunctivism, in paradigm cases of perceptual knowledge, one's knowledge that $p$ is grounded in one's seeing that $p$, and one can, by reflection alone, come to know that they see that $p$. In this paper, I argue that the epistemic conception of introspective indiscriminability is incompatible with epistemological disjunctivism, so understood. This has the consequence that theories of the nature of sensory experience which accept the epistemic conception of introspective indiscriminability - such as phenomenal character disjunctivism and certain forms of naïve realism - are inconsistent with epistemological disjunctivism, so understood. I then argue that proponents of epistemological disjunctivism face a formidable challenge explaining in what sense, if any, one can have purely reflective knowledge of their factive rational support.
\end{abstract}

Keywords Epistemological disjunctivism - Metaphysical disjunctivism - Introspective indiscriminability $\cdot$ Reflective knowledge $\cdot$ Naive realism

\section{Introduction}

Epistemological disjunctivism is the thesis that the nature of your rational support for your external world belief that $p$ in the good case is different from the nature of your rational support, if any, for your belief that $p$ in the bad case. ${ }^{1}$ In his recent work, Duncan Pritchard

\footnotetext{
${ }^{1}$ For this characterization of epistemological disjunctivism, see Pritchard (2015). See also French (2016). Alternative characterizations of the view are possible as well. For example, one can express epistemological disjunctivism as the thesis that there is a difference in the strength of one's epistemic support for their target belief that $p$ in the good case and bad case. If this is sufficient for being a version of epistemological disjunctivism, then every theory inconsistent with the New Evil Demon thesis constitutes as form of epistemological disjunctivism, which might be too liberal. Rather, it needs to be restricted not to one's total epistemic support at a time $t$ for one's belief that $p$, but crucially only those epistemic properties which supervene on one's mental properties.
}

Chris Ranalli

c.b.ranalli@vu.nl

1 Department of Philosophy, Vrije Universiteit Amsterdam, De Boelelaan 1105, 1081 HVAmsterdam, The Netherlands 
has defended a form of epistemological disjunctivism (henceforth ED) which characterizes the nature of the rational support for your belief that $p$ in the good case as follows: your rational support is factive (because it consists in seeing that $p$, and seeing that $p$ entails $p$ ) and accessible through introspective reflection alone (because you can come to know, by reflection alone, that you see that $p$, and that this is your reason for believing that $p$ ).

Why believe ED? The main reasons are that ED promises to bring together core elements of epistemic internalism and epistemic externalism, ${ }^{2}$ that it resolves the problem of radical skepticism in a satisfying way, ${ }^{3}$ and because it gives a satisfactory theory of perceptual knowledge which captures elements of our ordinary epistemic practices. ${ }^{4}$ Naturally enough, it faces a number of challenges. ${ }^{5}$ This paper presents a challenge which is different from the others so far presented against ED, which have targeted the specifically epistemological commitments of the view. In particular, this problem highlights a tension between ED and certain theses about the metaphysics of mind. The main challenge is that it cannot be consistently combined with the epistemic conception of introspective indiscriminability - a modest and intuitively plausible conception of such indiscriminability (see Martin 2004, 2006). The major import of this consequence, as we will see, is that ED is in tension with naïve realism about perceptual experience, since such a conception of indiscriminability is plausibly thought to be necessary for defending naïve realism from the objection that, during cases of perfect hallucination, your mental state can have the same phenomenal character as it does during veridical perception (see Martin 2002 , 2004, 2006, 2007; more on this in \$6). Since naïve realism is one of the primary reasons for supporting metaphysical disjunctivism, it turns out that there is an inconsistency between epistemological disjunctivism and certain varieties of metaphysical disjunctivism as well, contrary to what many epistemologists may have initially thought (Pritchard 2012, Byrne and Logue 2008; more on this in §6). Finally, the total package of ED and metaphysical disjunctivism displays a certain kind of theoretical unity: both our perceptual reasons and our perceptual experiences can include ordinary external things as constituents. ${ }^{6}$ Intuitively, it would be a disappointing result to find out that no such unified metaphysical and epistemological theory is forthcoming. ${ }^{7}$

\footnotetext{
2 See Pritchard (2012), pp. 1-4.

3 ibid., pp. $125-150$.

${ }^{4}$ ibid., pp. 17-18.

${ }^{5}$ In his (2012), Pritchard tried to show that the main challenges facing epistemological disjunctivism can be overcome. The subsequent literature has tended to focus on these problems: the basis problem, the distinguishability problem, and the access problem. For critical responses to Pritchard's $(2011,2012)$ response to the basis problem, see French 2016, 2012), Ghijsen (2015), and Ranalli (2014). For a critical response to the distinguishability problem, see Boult (2017). For critical responses to the access problem, see Kraft (2015). For whether Pritchard's form of ED can satisfactorily handle Cartesian skepticism, see Goldberg (2016) and Zalabardo (2015). For whether ED can satisfactorily handle the new evil demon problem, see Madison (2014). For a more holistic critique of Pritchard's (2012) epistemological disjunctivist project, see Littlejohn (2016).

${ }^{6}$ By 'constituent', I just mean partial constitution. So, the thought is that ED implies that your perceptual reasons in paradigmatic cases of perceptual knowledge can be states of mind like seeing that you have hands. I take it that a constituent part of your perceptual reason here is your hands. Naïve realism about perceptual experience implies that in paradigmatic cases of veridical perceptual experience, such as when you see your hands in broad daylight, your hands is a constituent part of your visual experience at that time.

${ }^{7}$ Importantly, if the main argument I propose is sound, it would show that a certain form of metaphysical disjunctivism and ED, so understood, are inconsistent. This is the naïve realist or relationalist form of metaphysical disjunctivism. Another form of metaphysical disjunctivism, what I call "representational metaphysical disjunctivism" in $\S 4$, would still be, prima facie at least, consistently combinable with ED.
} 
My main argument can be summarized as follows. First, ED is inconsistent with the epistemic conception of introspective indiscriminability. Roughly, this is the thesis that introspective indiscriminability is the impossibility of knowing, by reflection alone, any non-trivial differences between mental states. This is interesting in its own right, but what makes it especially interesting for proponents of ED is that certain theories of the nature of perceptual experience, such as phenomenal character disjunctivism, take the epistemic conception of introspective indiscriminability as a commitment of the view (see Fish 2010; cf. Martin 2004, 2006). So, prima facie at least, the result is that ED and phenomenal character disjunctivism are inconsistent. Secondly, however, if proponents of ED opt for the phenomenal conception of introspective indiscriminability instead, this too makes their view inconsistent with phenomenal character disjunctivism. Thirdly, proponents of ED might need to revise their conception of introspective indiscriminability in response to this argument, or else accept that their view is inconsistent with phenomenal character disjunctivism. Both options are of course available to the proponent of ED. However, I'll argue that the first option puts considerable pressure on them to revise their views about reflective self-knowledge, and the second option makes ED less metaphysically neutral than it was otherwise advertised as being (see Pritchard 2012; Byrne and Logue 2008).

Here's the structure of the paper. In section 2, I explain what epistemological disjunctivism is, and, in particular, Pritchard's $(2012,2015)$ version of epistemological disjunctivism (ED). In section 3, I explain why the epistemic conception of introspective indiscriminability and ED are inconsistent. The next two sections seek to defend the premises of that argument. So, in section 4, I argue that proponents of ED should maintain that propositional perceptual states, such as seeing that $p$, are mental states. In section 5, I defend the premise that reflective knowledge of your current mental state requires reflective knowledge that they are not merely perfect 'ringers' or 'copies' for what you take them to be. In section 6, I consider the phenomenal conception of introspective indiscriminability, and I argue that this view is inconsistent with phenomenal character disjunctivism. The upshot is that, if the proponent of ED accepts the phenomenal conception of introspectively indiscriminability instead of the epistemic conception, then they should deny phenomenal character disjunctivism. Section 7 considers a detailed reply from proponents of the distinction between favoring and discriminating epistemic support as a way of avoiding the tension between the epistemic conception of introspective indiscriminability and ED. I argue that the application of that distinction to purely reflective knowledge of your mental states cannot be plausibly sustained.

\section{Epistemological Disjunctivism}

Epistemological Disjunctivism can be expressed as a thesis about the nature, or the strength, of one's rational support in a pair of cases. ${ }^{8}$ The first case is one in which the

\footnotetext{
${ }^{8}$ Two notes: first, I'm following Pritchard in his use of 'rational support', which I take to mean epistemically rational support, that is, it supports taking a doxastic attitude toward the truth-value of a proposition, such as belief. Secondly, in his earlier work on epistemological disjunctivism, Pritchard tended to formulate ED in terms of the strength of one's rational support. Since his (2012), however, he has characterized ED in terms of the kind of rational support that it is. See Pritchard $(2015,2016)$.
} 
agent counts as having a veridical perception, and, on this basis, comes to know that $p$. This is the good case. In the second case, the agent has an introspectively indiscriminable hallucination, and, on this basis, comes to believe that $p$ but fails to know that $p$ because $p$ is false. According to the epistemological disjunctivist about the nature of one's rational support in these cases:

Different Nature: the nature of one's rational support for $p$ in the good case is different from the nature of one's rational support for $p$ in the bad case.

In particular, the proponent of epistemological disjunctivism who frames their negative thesis in terms of a difference in the nature of the rational support in the good case and the bad case thinks that the rational support one has in the good case picks out a kind or species of rational support which is never available in the bad case. On the other hand, an epistemological disjunctivist might instead frame their negative claim in terms of the strength of one's rational support in these cases:

Different Strength: the strength of one's rational support for $p$ in the good case is different from the strength of one's rational support for $p$ in the bad case (namely, one's rational support in the good case for $p$ is better than one's rational support in the bad case for $p$ ).

Now, you should ask why one would think that the rational support for your external world belief in the good case is better than your rational support for the same belief in the bad case. One reason that might be offered is that your external world belief enjoys no rational support in the bad case, and thus your rational support in the good case is trivially better than your rational support in the bad case.

Another reason why the epistemological disjunctivist might hold that your rational support for $p$ in the good case differs in strength from your rational support for $p$ in the bad case is that, in the good case, your rational support is factive (it entails that $p$ ) and you are in a position to know, by reflection alone, that you have such a rational support for $p$. So, this strategy compares the epistemic properties of the two cases, consistently with the idea that there are epistemic properties relevant to your external world belief that $p$ in the bad case, and says that the epistemic properties of the good case are better than the bad case. In effect, the proponent of this way of thinking about your rational support in the good case says that, everything else being equal, factive epistemic reasons are better than non-factive epistemic reasons. ${ }^{9}$

\footnotetext{
${ }^{9}$ Note that this view, that ceteris paribus factive epistemic reasons are better than non-factive epistemic reasons, looks intuitively plausible but a story will need to be given for why it's true. One story that could be given is that the reason why we want our beliefs to be based on good reasons is that good reasons are indicators that our beliefs are likely to be true, and truth is the cognitive goal of belief (cf. Bonjour 1985). So, the thought is that factive reasons serve this cognitive goal par excellence, and are thereby better than reasons which fall short of serving the goal perfectly. However, you might also think that factive reasons aren't necessarily better than non-factive reasons if you are comparing reasons one-to-many and not only one-to-one. For example, it might be that a set of non-factive reasons for believing $p$ is overall better reason to believe that $p$ than a single factive reason is to believe that $p$, although the latter serves the cognitive goal of belief better than the former.
} 
Finally, the epistemological disjunctivist underwrites their negative thesis with a positive thesis:

[...] in paradigm cases of perceptual knowledge the knowledge in question enjoys a rational support that is both factive and reflectively accessible. In particular, it is the view that when one has perceptual knowledge in such cases, the reflectively accessible rational support one has for one's knowledge that $p$ is that one sees that $p$ (Pritchard 2015: 124).

The thought is that the positive thesis can explain why one's rational support in the good case and the bad case are not just two distinct instances of the same kind of rational support, but rather instances of two distinct kinds of rational support. After all, one might think that the properties <being a factive rational support $>$ and < being a non-factive rational support $>$ is a difference which carves rational support kinds at the joints.

\section{Epistemological Disjunctivism and the Epistemic Conception of Introspective Indiscriminability}

What is it for two mental states or events to be introspectively indiscriminable for a subject? Proponents of the epistemic conception of introspective indiscriminability accept the following equivalence thesis:

Epistemic Conception of Introspective Indiscriminability: For all $S$, and any occurrent mental states $m$, a mental state $m_{1}$ is introspectively indiscriminable from $m_{2}$ if and only if $S$ is not in a position to know, by reflection alone at that time, that $m_{1}$ is not $m_{2}$ and vice-versa. ${ }^{10}$

Why accept the epistemic conception of introspective indiscriminability? One of the main reasons is that it seems to avoid controversial ontological commitment in cases of hallucination. On the epistemic conception of introspective indiscriminability, it's not the case that there has to be a difference in the nonepistemic properties of $m_{1}$ and $m_{2}$ in order for them to be introspectively indiscriminable for you. So, the theory doesn't presuppose that, say, during a bad case in which you are suffering a perfect hallucination which is introspectively indiscriminable from a veridical perception, there is some commonality in the sense-data that you are sensorily aware of, such as being sensorily aware of the same sense-data, or that there is some commonality in the representational content of your experiences, such as being the same representational content. It's entirely neutral on those ontological questions. Intuitively, this is a virtue of the view.

\footnotetext{
${ }^{10}$ Cf. Siegel's (2008) definition: " $\mathrm{X}$ is indiscriminable from $\mathrm{Y}$ by a subject $\mathrm{S}$ at time $\mathrm{t}$ iff $\mathrm{S}$ cannot know at time $\mathrm{t}$ by introspection alone that $\mathrm{X}$ is not $\mathrm{Y}$ " (Siegel 2008: 209). For criticisms of this theory in connection with naïve realism and disjunctivism, see Siegel (2008, 2010). See also Byrne and Logue (2008: 58) for this definition.
} 
Moreover, some philosophers of perception think that the epistemic conception of introspective indiscriminability is necessary in order to make sense of certain disjunctivist views about the metaphysics of experience (see Martin 2004, 2007; see Fish 2010 for an overview. More on this in §6). On Martin's view, for example, the epistemic conception of introspective indiscriminability is necessary for naive realism about sensory experience (see Martin 2004: 82). Finally, some philosophers have appealed to the epistemic conception of introspective indiscriminability in order to motivate certain forms of epistemic externalism, and certain theses about vagueness (see Williamson 2000, 2013).

I won't be assessing whether the epistemic conception of introspective indiscriminability is plausible. In this section, I'll argue only that the epistemic conception of introspective indiscriminability and ED are prima facie inconsistent.

Here, then, is the argument:

(P1) A mental state $m_{1}$ is introspectively indiscriminable from $m_{2}$ for $S$ at $t$ if and only if $S$ is not in a position to know at $t$, by reflection alone, that $m_{1}$ is not $m_{2}$.

(P2) The mental state you have in the good case, $m_{1}$, whereby you know that $p$ on the basis of seeing that $p$, is introspectively indiscriminable from your mental state in the bad case, $m_{2}$, where you merely seem to see that $p$ but fail to know that $p$.

From (P1) and (P2):

(C1) You are not in a position to know, by reflection alone, in the good case, that $m_{1}$ is not $m_{2}$.

Now we add the following three premises:

(P3) If ED is true, then you can know, by reflection alone, in the good case, that you see that $p$.

(P4) The seeing that $p$-state is your mental state in the good case and the mere seeming to see that $p$-state is your mental state in the bad case.

(P5) If you are not in a position to know, by reflection alone, in the good case, that your seeing that $p$-state is not merely a seeming to see that $p$-state, then you cannot know, by reflection alone, in the good case, that you see that $p$.

From $(\mathrm{C} 1)$ and $(\mathrm{P} 4)$, it follows that:

(C2) You are not in a position to know, by reflection alone, in the good case, that your seeing that $p$-state is not a mere seeming to see that $p$-state.

From modus ponens on (P5) and (C2), it follows that:

(C3) You cannot know, by reflection alone, in the good case, that you see that $p$. 
From modus tollens on (C3) and (P3), it follows that:

(C) ED is false.

The argument is valid. So, the main question is whether the premises are adequately supported. Premise (P2) expresses a relatively uncontroversial thesis about one's mental states in the good and bad cases. Premise (P3) expresses a core commitment of ED. ${ }^{11}$ So, those premises will be left unexamined.

The main premises we will need to examine, then, are the first premise (P1), which expresses the epistemic conception of introspective indiscriminability; premise (P4), which expresses the view that seeing that p-states are mental states, and finally premise (P5), which links the inability to reflectively know that your mental state is not a mere 'ringer' for it - e.g., that it's not merely a seeming state-with the inability to reflectively know that you are in the mental state you believe yourself to be in (e.g., a seeing that $p$-state). So, the proponent of ED will need to either deny the epistemic conception of introspective indiscriminability, deny the thesis that seeing that $p$-states are mental states, or else deny that there is such a link between reflective knowledge of one's mental states with reflective knowledge that they aren't merely ringers for such mental states. As we'll see, I'll argue that every option comes with a heavy price for proponents of ED to pay.

\section{Are Propositional Perceptual States Mental States?}

According to (P4), your mental state in the good case is your seeing that $p$-state whereas it's a ringer for that kind of state in the bad case - that is, it's a mere seeming of being in such a state (e.g., seeming to see that $p$; cf. McDowell 1995). In this section, I want to defend (P4).

First, some stage setting. Notice that ordinary perception-reports suggest that we can distinguish between objectual perceptual states and propositional perceptual states (see Dretske 1969; Cassam 2007a, b; French 2012; Stroud 2011). For example, consider the following visual perception-ascriptions: 'you saw an open bank', and 'you saw that the bank is open'. Taking the verb-phrases to denote visual states of mind, the latter, but not the former, looks like it denotes a factive propositional attitude. That is, that you merely see an open bank doesn't entail that you take any propositional attitude with respect to the bank which is open, whereas seeing that the bank is open intuitively seems to entail not only that there is a bank which is open, but that you take some kind of propositional attitude towards it. Of course, both states have existential commitment: you cannot see an open bank unless there exists an open bank that you see, just as you cannot see that the bank is open unless there is a bank which is open.

Intuitively, propositional perceptual states at least seem to have epistemological properties that objectual perceptual states lack. In particular, seeing that the bank is open seems to entail not only that the bank is open, but that you know that it's open. ${ }^{12}$

\footnotetext{
${ }^{11}$ See Pritchard (2012).

${ }^{12}$ However, see the arguments from Pritchard (2011); McDowell (2002); Turri (2010) against this view. For responses, see Ranalli (2014) and French (2012). For advocates of such an entailment thesis, see Williamson (2000); Stroud, (2011); Dretske (1969); Cassam (2007a, b).
} 
But it doesn't seem this way if you simply see an open bank. Simply seeing something doesn't even seem to entail that you know anything about it. For you might see an open bank and yet fail to have the concept of a bank, or the predicational concept of being open. Still, intuitively you can see an open bank even if you lack the concept of a bank. It's at least less obvious that this could be true of seeing that the bank is open. After all, it strikes us as odd - if not inconsistent - to maintain that one sees that the bank is open but doesn't know what a bank is; or that one sees that it's open but fails to even believe it. At a minimum, seeing that the bank is open involves representing that the bank is open, whereas this is less clear for merely seeing an open bank. This is all part of what we might call the "phenomenology" of propositional perceptual states (e.g., seeing that $x$ is F) and the "phenomenology" of objectual perceptual states (e.g., seeing an $x$ which is F): they inform our initial theorizing about these states, even if, in the end, they need to be revised.

Now one might wonder whether propositional perceptual states, such as seeing that $p$-states, are mental states (see Williamson 2000 for the view that they are). According to views like naive realism, objectual perceptual states at least are mental states. Seeing an open bank is a mental state on this view because seeing itself is a conscious awareness relation to external physical things (cf. Martin 2004, 2007. See also Campbell 2002; Fish 2009). And consciousness (or conscious awareness of...) is a paradigmatic mental state. When you see an open bank, on this view, you enter into a relation of conscious awareness with the open bank, such that the open bank becomes a constituent of your visually conscious state of mind at that time. Ordinary seeing, for the naive realist, is what we might call a fundamentally visually conscious "relational" mental state. But, for all that, it's still a mental state.

Yet most philosophers of perception are not naive realists. Most philosophers of perception maintain that objectual perceptual states are compositional states: part mental, part non-mental. The mental part is the conscious sensory experience (whether one thinks of this as a representational state, or a conscious state with adverbial modification, or a relational state to sense-data; or some combination of these), whereas the non-mental part is the object that one sees and various bodily causal intermediaries. So, for most philosophers of perception anyway, objectual perceptual states are not mental states. ${ }^{13}$

What about propositional perceptual states? This is a more delicate question. First, we need to distinguish between different kinds of propositional perceptual state reports. Some ascriptions of ' $S$ sees that $p$ ' are devices for marking that $S$ knows that $p$, such as when you see that things are getting worse, not better. In such cases, you might be blindfolded, but the ascription 'you see that $p$ ' (for certain propositions $p$, like that things are getting worse), could still be true of you at that time. Seeing, conceived as a fundamentally visual state of mind, isn't necessary for it to be true that you see that $p$, in this sense. Seeing that $p$, in this sense at least, is a mental state only if knowing that $p$ is a mental state. This is the "pure epistemic"-use of ' $S$ sees that $p$ '-ascriptions (see Gisborne 2010; cf. French 2012, 2013).

Another, related use of ' $S$ sees that $p$ ' is to mark that $S$ knows that $p$ on the basis of vision (or visual experience; see French 2013). This takes us closer to the view that such ascriptions are ascriptions of mental states. But, still, it turns on whether one wants

${ }^{13}$ See Williamson (2000) for the view that arguments, like the one sketched above, are fallacious. 
to count seeing that $p$-states as being mental states because visual experiences are mental states or not. One might hold that seeing that $p$, although it is in part a visual mental state, is nevertheless composed of non-mental parts as well, and that this is sufficient for making it not a mental state.

What these suggestions motivate is the idea that moving from premises about ' $S$ sees that $p$ '-ascriptions and premises about the ontology of seeing that $p$-states, to the thesis that seeing that $p$-states are mental states, will be controversial. So, we shouldn't expect to find uncontroversial arguments or evidence for the thesis that seeing that $p$-states are mental states from the ontology of mind or the theory of perception-reports.

Perhaps a better place to focus is on the proponent of ED's commitment to reflective access, and specifically reflective propositional knowledge of one's seeing that $p$-states. That is, rather than focusing on whether or not there's a general argument from premises about the ontology of mind or the theory of perception reports for the thesis that seeing that $p$-states are mental states, we should focus only on whether proponents of ED specifically are committed to the thesis that seeing that $p$-states are mental states. So, let's raise that question: are proponents of ED committed to this thesis? I think it's very difficult for them to avoid this commitment. ${ }^{14}$ After all, it's hard to see how one could have purely reflective access to something which is not a mental state or part of one's mental state. ${ }^{15}$ The main idea here is that anything within the scope of our reflective access are states of mind and certain conscious proprioceptual states, if these aren't themselves mental states (e.g., certain joint positions and one's sense of location and motion). Since the proponent of ED maintains that seeing that $p$ states can be within the scope of our reflective powers, this is a prima facie reason for thinking that the proponents of ED are committed to the thesis that seeing that $p$-states are mental states. ${ }^{16}$ And in locating the objects of reflective access 'in the mind', proponents of ED are not thereby committed to the metaphysical thesis that whatever is 'in the mind' is behind the skull, or that whatever is 'in the mind' supervenes only one's biological brain and bodily states. In short, in saying that

\footnotetext{
${ }^{14}$ Haddock and Macpherson (2008) describe McDowell's form of epistemological disjunctivism as taking seeing that $p$-states to be sensory mental states. They say: "McDowell appears to argue that there can be experiences with such content "only because when [our experiences] are the upshot (in a suitable way) of the fact" that $p$ (McDowell 1983: 389), our experiences are states of seeing that $p$ " (Haddock and Macpherson 2008: 8).

${ }^{15}$ Indeed, this is heart of the "access problem" for epistemological disjunctivism. See Pritchard (2012) pp. 4652. Pritchard's solution to the access problem is not to accept that one can have knowledge of facts about one's environment through reflection alone, but rather that one can come to know, through reflection alone in certain kinds of good cases (see Pritchard 2012, p. 29 for what he calls the "good+ case"), that one's empirical reason for $p$ entails that their corresponding belief that $p$ is true.

${ }^{16}$ One might think that the following principle is true: for all $x$, if $x$ is reflectively accessible, then $x$ is a mental state or constitutively dependent on a mental state (e.g., it's a property of a mental state). I don't think this principle is true. There is a sense of 'reflectively accessible' in which numbers and other mathematical and logical entities and relations are reflectively accessible, but I don't think that's yet any reason to think that they are mental or properties of anything mental. Still, according to proponents of ED, seeing that $p$-states can be reflectively accessed, and since there's no reason whatsoever to think that seeing that $p$-states are abstract (like numbers and sets, for example), or, modulo idealism, some state of the non-psychological world, this puts pressure on proponents of ED to count them as mental states. In short, the reasoning in the main text isn't appealing to any general principle linking the reflectively accessible with the mental. Instead, it's linking the reflectively accessible with the mental when there are no other good candidates for what the reflectively accessible state could be.
} 
proponents of ED should locate the objects of reflective access within the subject's mind, this isn't to say that proponents of ED need to deny externalism about the mental, that at least some states of mind fail to supervene only on the subject's intrinsic states (e.g., states of the subject's brain and body).

Now one might think that this view is at odds with the transparency of experience. According to this objection, experience is transparent: introspection of your experiences doesn't reveal the experience itself or some mind-dependent properties, but rather aspects of your immediate external environment. Thus, so the objection goes, introspection of your experience at some time is introspection of something non-mental, namely, aspects of your external environment at that time. So, it's not the case that what you come to know by introspective reflection alone is only states of your mind, but rather states of the external world.

Even if we think that perceptual experience is transparent, in the sense that your introspection of your experience seems to present your immediate environment to you, ${ }^{17}$ this is consistent with such mental states, so understood, not putting you in a position to know about your immediate external environment. That is, it's consistent with the reflective accessibility of such states not implying any knowledge of any specific facts about the non-psychological world. Transparency, after all, is a property of mental states. Your perceptual experiences can have the property of being transparent - as seeming to present the external environment around you-even if, in fact, they fail to reveal your external environment. Put simply: the transparency of perceptual experience of your external environment doesn't entail perceptual knowledge of your external environment.

Moreover, even if, by being transparent, the sensory experience that you have reflective access to revealed the world around you-revealing, say, a lump of nonpsychological objects, properties, and relations, such as an open bank - this presentation isn't sufficient for knowing that the bank is open or even that it's a bank. Other, more complex tasks, would need to be undertaken: recognizing the object as a bank (as falling under the concept bank), or attributing the concept of being open to the seen object, the object you visually recognize as a bank. Propositional knowledge is a propositional attitude, even if knowing-how and knowing-where are not. One needs to grasp a proposition to know that something is so, but one doesn't need to grasp a proposition to just see something. This and the epistemic conditions for knowledge which must be met - believing, and the truth of one's belief not being the product of luck - make it hard to see how if one introspects on what their current sensory experience is like for them, and their experience in fact reveals parts of their external environment (if one wants to understand the transparency of perceptual experience in this strong sense: as actually revealing aspects of their environment), this is not plausibly sufficient for coming to know certain truths about one's environment. Intuitively, you could see an open bank, such that your experience reveals that part of your environment to you, and you reflect on what it's like to enjoy such an experience at the time, whereby you become directed upon the open bank, but nevertheless fail to

\footnotetext{
${ }^{17}$ Not all philosophers of mind think that the transparency of experience should be explained by one's experience having representational content. For example, see Martin (2002) for the view that naive realism is just as well positioned (if not better positioned) to explain transparency as content theories. For work on how transparency supports content theories of perceptual experience, see Tye (2002)
} 
perceptually know that the bank is open. For you might have run through this task without yet knowing what an open bank even is. So, the transparency of perceptual experience is consistent with the idea that when you introspectively reflect on your current veridical perceptual experience, you don't thereby come to know about the world around you.

The argument here is meant to block the view that the kind of introspective access you have to your seeing that $p$-states is introspective access to facts about the environment and your relation to it, but not facts about your mind as well. The blocking move is meant to explain how reflective access, and knowledge based on that, is possible for the proposition that one sees that $p$, without this being a species of self-knowledge or knowledge of one's mind. I argued that one might try to make sense of this idea by arguing that some states of mind are transparent, and that, in veridical cases of perceptual experience, reveal one's ordinary external environment. However, I argued that introspective access to one's veridical perceptual states wouldn't be sufficient for propositional knowledge of one's environment, even if those states, by being transparent, reveal one's environment.

In summary: I've argued that proponents of ED ought to view seeing that $p$-states as mental states in order to make sense of their commitment to seeing that $p$-states being knowable by reflection alone. The trouble for proponents of ED is that this allows the conclusion of the main argument to stand, and thus puts pressure on the proponent of ED to either reject the epistemic conception of introspective indiscriminability or the link between reflective knowledge of one's mental states with reflective knowledge that such states aren't merely ringers.

\section{Reflective Knowledge and Knowledge of the Denials of Error-Possibilities}

In the previous section, I defended the thesis that propositional perceptual states, like seeing that $p$, are mental states. In particular, I argued that proponents of ED should take such states to be mental states. This supports (P4), which identifies your mental state in the good case so characterized as a seeing that $p$-state.

Premise (P5) connects reflective knowledge of your current mental state with reflective knowledge of the denials of error-possibilities for that mental state. Applied to the main argument, it connects knowledge of your mental state-your seeing that $p$ state - with knowledge of the denials of potential ringers for that kind of mental statesuch as mere seeming to see that $p$-states:

(P5) If you are not in a position to know, by reflection alone, in the good case, that your seeing that $p$-state is not merely a seeming to see that $p$-state, then you cannot know, by reflection alone, in the good case, that you see that $p$.

(P5) is intuitively plausible. Suppose you believe that your state of mind right now is what you think it is. For example, perhaps it's a veridical visual experience of the text of this paper. Now consider the possibility that you are merely visually hallucinating this, such that it seems to you just as if you are reading the text of this paper. Intuitively, 
you need to be able to exclude this possibility if you really do know that you are in the mental state you think you're in right now.

Although I think (P5) is intuitively plausible, it might lead to intuitional gridlock. Perhaps some people will find it utterly incredible that knowledge of your current mental state requires knowledge of the denials of ringers for your current mental state. In order to avoid intuition-based gridlock, then, we can support (P5) by way of a closure principle for reflective knowledge - knowledge achieved by reflection alone (henceforth ' $\mathrm{know}_{\mathrm{RK}}$ '):

Closure Principle $_{\mathrm{RK}}$ : If you know $\mathrm{RK}_{\mathrm{K}}$ that $\mathrm{P}$, and you know $\mathrm{RK}_{\mathrm{K}}$ that $\mathrm{P}$ implies $\mathrm{Q}$, then you are in a position to $\mathrm{know}_{\mathrm{RK}}$ that $\mathrm{Q}$.

This supports (P5) as follows. First, suppose you know $\mathrm{RK}_{\mathrm{R}}$ that you see that $p$. You can easily know $\mathrm{RK}_{\mathrm{R}}$ that you seeing that $p$ implies that you don't merely seem to see that $p$, since you can know by reflection alone that they are incompatible. After all, if you see that $p$, you don't merely seem to see that $p$. So, by the closure principle $\mathrm{RK}_{\mathrm{RK}}$, you are in a position to nnow $_{\mathrm{RK}}$ that you don't merely seem to see that $p$. With this principle in play, we can easily yield the conditional: if you know $_{\mathrm{RK}}$ that you see that $p$, then you are in a position to know $\mathrm{RK}_{\mathrm{R}}$ that you don't merely seem to see that $p$ (alternatively: that your seeing that $p$-state is not merely a seeming to see that $p$-state). Contraposed, we get (P5): if you are not in a position to know ${ }_{\mathrm{RK}}$ that you don't merely seem to see that $p$, then you do not know $\mathrm{RK}_{\mathrm{R}}$ that you see that $p$ (e.g., explicitly: if you are not in a position to know $\mathrm{RK}_{\mathrm{RK}}$ that your state of mind is not merely a seeming to see that $p$-state, then you don't know $_{\mathrm{RK}}$ that your state of mind is a seeing that $p$-state).

It is open to the proponent of ED to simply reject (P5), but the cost is the rejection of the closure principle $\mathrm{RK}_{\mathrm{RK}}$. This would be a strange result for proponents of ED, since on that view you can know $_{\mathrm{RK}}$ that you see that $p$. Moreover, knowing $_{\mathrm{RK}}$ that such a state is incompatible with merely seeming to be in that state is intellectually undemanding: it is not more demanding than knowing that you have hands is incompatible with that you're not a handless brain in a vat, which is typically taken to be innocuous. So, it's not clear what principled reason would prevent the proponent of ED from thinking that, given those two facts, you would be in a position to know $\mathrm{RK}_{\mathrm{K}}$ that the relevant ringer error-possibility does not obtain (we'll return to this issue in $\S 7$ ).

Likewise, the closure ${ }_{\mathrm{RK}}$ principle should be appealing to anyone who already thinks that single-premise closure principles are appealing. Indeed, one of Pritchard's (2012, 2015) methodological constraints is the preservation of various epistemic closure principles (see Pritchard 2015, where he seeks to preserve closure for knowledge and 'rationally grounded' knowledge). And the reasoning in support of (P5) is structurally similar to the reasoning for the following sorts of conditionals-based on closure principles — such as that:

- If you know that you have hands, then you know you're not a handless brain in a vat.

- If you know that there's a zebra in the pen, then you know it's not merely a cleverly disguised mule.

Since the reasoning for (P5) is structurally similar to the reasoning for those conditionals, by parity of reasoning it's hard to see why one would accept it in those 


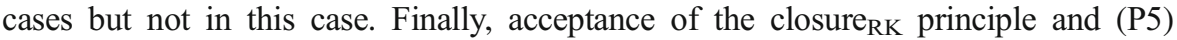
needn't have any skeptical consequences for reflective knowledge, since it doesn't yet establish that you cannot know $_{\mathrm{RK}}$ the denials of the ringer hypotheses for your current mental states. It only seeks to connect knowledge $\mathrm{RK}_{\mathrm{RK}}$ of your mind with knowledge $\mathrm{RK}_{\mathrm{RK}}$ of the denials of certain error-possibilities for your states of mind, in just the same way that other closure principles seek to connect knowledge of the world with knowledge of the denials of certain error-possibilities for your beliefs about the world. In $\S 7$, I'll return to this premise in order to reply to a potential objection on behalf of the proponent of ED.

\section{Epistemological Disjunctivism and Phenomenal Character Disjunctivism}

Metaphysical disjunctivism is the thesis that the nature of your sensory mental state in the good case is different from the nature of your sensory mental state in the bad case (cf. French 2016). You can develop this thesis in at least two different ways. One way is to argue that what your sensory experiences represent in the good and bad cases are different, and that this difference is sufficient for the experiences to have a different nature. This is representational content disjunctivism (see McDowell 1995, 1983, 1986). A different way of developing metaphysical disjunctivism is to argue that your experiences have different phenomenal properties in the good and bad case, and that this difference is sufficient for your sensory experiences in those cases to have a different nature. In turn, phenomenal character disjunctivism is the thesis that the phenomenal character of your sensory mental state in the good case is different from the phenomenal character of your sensory mental state in the bad case (cf. Fish 2010: 94). As Fish (2010) highlights, phenomenal character disjunctivism seems to be at odds with otherwise intuitively plausible ideas about the introspective indiscriminability of your mental states in the good and bad case:

[...] disjunctivism about phenomenology can [...] seem strange: perceptions and hallucinations are accepted to be indiscriminable. Doesn't this just entail that they have the same phenomenal character? (Fish 2010: 95).

Phenomenal character disjunctivists, then, should deny that introspective indiscriminability is sufficient for the target introspectively indiscriminable states to have the same phenomenal character. But that raises the following question: how can the phenomenal character disjunctivist account for the fact that perceptual experiences and perfect hallucinations are introspectively indiscriminable? To see this, consider a good case of seeing an $x$ which is $F$ and a bad case of suffering a visual hallucination as of an $x$ which is $F$. We might think that both the seeing and the hallucination count as a visual experience. So, you might think they are introspectively indiscriminable from each other by virtue of being visual experiences with the same phenomenal properties. After all, intuitively what it is like for you to undergo either experience is the same. This is the phenomenal conception of introspective indiscriminability. ${ }^{18}$ Clearly, phenomenal character disjunctivists cannot accept this view, as they deny that your sensory

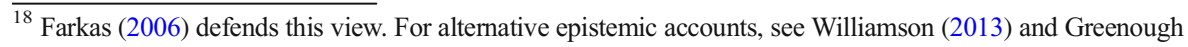
(2012). 
experiences in the good and bad cases have the same phenomenal properties. So, the proponents of phenomenal character disjunctivism will say that a sensory experience $m$ in the bad case is a sensory experience of an $x$ which is $F$ if and only if $m$ is introspectively indiscriminable from a veridical sensory perception of an $x$ which is $F$. The strategy of the phenomenal character disjunctivist is to say that your experience in the good case has a certain nature, but your experience in the bad case counts as an experience only by reference to your experience in the good case. In this way, perfect hallucinations don't have a metaphysical nature of their own. Rather, their nature is parasitic on the nature of your experience in the good case.

Who defends the epistemic conception of introspective indiscriminability? According to naive realists:

[...] the phenomenal character of your experience, as you look around the room, is constituted by the actual layout of the room itself: which particular objects are there, their intrinsic properties, such as color and shape, and how they are arranged in relation to one another and you (Campbell 2002: 116)

\section{In particular:}

[...] some sensory experiences are relations to mind-independent objects. That is to say, taking experiences to be episodes or events, the naïve realist supposes that some such episodes have as constituents mind-independent objects (Martin 2006: 354)

According to Martin, phenomenal character disjunctivism provides one with a way of preserving naive realism about the nature of perceptual experience. The disjunctive element of metaphysical disjunctivism is a thesis about how to understand what sensory experience is (and, in turn, what the truth-conditions for sensory experience-reports are). For example, that $S$ has a visual experience as of $F$ should be understood as the disjunction: either $S$ sees something that is $F$ or it merely visually seems/appears to $S$ that there is an $F$. The left-hand side disjunct, the good disjunct, is given a naive realist characterization: it's a mental state that is an (at least two-place) relation of conscious awareness of an ordinary external physical entity (in this case, a relation to an $x$ which is $F$ ). And this external physical entity and one's relation to it (the conscious awareness relation to the $x$ which is $F$ ) explains the phenomenal character of one's mental state at that time. The right-hand side of the disjunct, the bad disjunct, is understood in purely epistemic terms. In particular, it is understood as a state which is not knowable by reflection alone to be distinct from the mental state one has in the good case. As Martin puts it: "such experiences have no positive mental characteristics other than their epistemological properties of not being knowably different from some veridical perception" (Martin 2004: 82). ${ }^{19}$

\footnotetext{
${ }^{19}$ One might wonder why the epistemic conception should be phrased in terms of knowledge rather than some other epistemic state. Williamson $(2013,2000)$ and Martin (2004) put it in terms of knowledge, but even if we defined introspective indiscriminability in terms of evidence or epistemic reasons, the prima facie inconsistency between the epistemic conception and ED would remain the same. After all, if it follows from the introspective indiscriminability between the good case mental state and the bad case state that, say, you lack evidence that the bad case state is not the good case state, that intuitively implies that you don't know by reflection alone that bad case state is not the good case state.
} 
What leads the phenomenal character disjunctivist to accept the epistemic conception over the phenomenal conception of introspective indiscriminability? In rough outline, the argument goes like this: suppose that the phenomenal character of your current visual perceptual experience is constituted by some of the visible features of the external physical objects and properties that you perceive. That is, suppose that naive realism about your visual experience is true. Now suppose that a visual experience $m_{1}$ is introspectively indiscriminable from your current visual experience $m_{2}$ if and only if $m_{1}$ has the same phenomenal character as $m_{2}$. Suppose now that $m_{1}$ and $m_{2}$ are introspectively indiscriminable for you, and that the visual experience you have by having $m_{1}$ is an hallucination (that is, the pair $m_{1}$ and $m_{2}$ are a bad and good case). It follows that $m_{1}$ 's phenomenal character is constituted by the visible features of the external physical objects and properties that you perceive. But this conflicts with the facts about $m_{1}$ being a perfect hallucination, whereby there are no candidate external physical things that you are consciously aware of. Assuming plausible theses about hallucination, then, it follows that naive realism and the phenomenal conception of introspective indiscriminability are inconsistent. Since naive realism is a thesis about the phenomenal character of sensory experience, and an essential part of phenomenal character disjunctivism, it thereby follows that phenomenal character disjunctivism and the phenomenal conception of introspective indiscriminability are inconsistent as well.

Now, one might wonder why this should lead one to endorse the epistemic conception of introspective indiscriminability. There are two reasons. First, proponents of phenomenal character disjunctivism and naive realism, such as Martin (2004, 2007), take the epistemic conception as a commitment of phenomenal character disjunctivism. For example, here's a representative claim:

[...] the second commitment of disjunctivism: (II) The notion of a visual experience of a white picket fence is that of a situation being indiscriminable through reflection from a veridical visual perception of a white picket fence as what it is (Martin 2006: 363)

The phrase 'being indiscriminable through reflection' is to be understood, in Martin's words, as " $\neg \backslash \mathrm{K}$ [through reflection]" (Martin ibid). That is, you have a visual experience of a white picket fence if and only if you cannot know by reflection alone that it isn't a veridical perception of a white picket fence. ${ }^{20}$

Secondly, it's hard to see how phenomenal character disjunctivism is consistent with any substantial metaphysical view about why your mental state in the good case is introspectively indiscriminable from the bad case. As Martin (2004) argues, if there is any metaphysical property $\mathrm{M}$ which is sufficient to explain the nature of your mental state in the bad case, then $\mathrm{M}$ will be explanatorily sufficient in the good case as well. After all, on pain of explanatory redundancy, why introduce a separate property $\mathrm{M}^{*}$ for the good case specifically if $\mathrm{M}$ all by itself could give us a metaphysical explanation of

\footnotetext{
${ }^{20}$ Martin expands on this a follows: "The situation in which you are knowingly having an hallucination of an orange is like a Cartesian situation in which you don't know of the hallucination, because, if we bracket that additional information, then what is available to you otherwise, i.e. what is available to you in simply reflecting on your circumstances, does not discriminate between the two situations. As we shall see [...] the import of this restriction and the consequences which flow from it are central to understanding what disjunctivism is committed to" (Martin 2006: 365).
} 
why the bad case is introspectively indiscriminable from the good case? This is a powerful reason for thinking that there is simply no metaphysical property $\mathrm{M}$ in the bad case which explains why your mental state in that case is introspectively indiscriminable from your mental state in the good case.

So, even though there might be logical space for views in between the phenomenal conception and the epistemic conception of introspective indiscriminability that phenomenal character disjunctivists could endorse-although this is not altogether clear, as per the argument above-paradigm examples of phenomenal character disjunctivism in the literature insist that the epistemic conception of introspective indiscriminability is a commitment of their view. ${ }^{21}$ This leaves us with the following result: if the proponents of ED accept the phenomenal conception as their account of what it is for two states to be introspectively indiscriminable from each other, then ED is inconsistent with phenomenal character disjunctivism as well.

Now, we saw that the proponents of ED who reject the epistemic conception, or otherwise opt for the phenomenal conception, are committed to the denial of phenomenal character disjunctivism. This places an interesting restriction on proponents of ED: they have to be disjunctivists about epistemic rational support, grounded in perceptual states, as per their view, without being disjunctivists about the phenomenal character of the perceptual states the rational support is grounded in. Perhaps the proponent of ED wants to avoid this restriction. If so, what options are available?

\section{Favoring vs. Discriminating Epistemic Support}

At least one further option we should explore is the distinction between favoring epistemic support and discriminating epistemic support (see Pritchard 2010, 2012, 2015). The basic claim is this: the thesis that you cannot know, by reflection alone, that your current mental state (e.g., seeing that $p$ ) is not a ringer for such a state (e.g., merely seeming to see that $p$ ) is ambiguous between reflective knowledge grounded in your introspective discriminatory capacities and reflective knowledge grounded in your favoring evidence. Indeed, Pritchard says this much:

the very idea of two scenarios being introspectively(/reflectively) indistinguishable is ambiguous between a reading in terms of discriminating support and a reading in terms of favouring epistemic support (Pritchard 2012, 96).

So, Pritchard's reply is that we need to distinguish between introspective indiscriminability as knowledge by reflection alone grounded in favoring support and knowledge by reflection alone grounded in introspective discriminating support, and that my main argument $(\S 3)$ conflates the two.

To understand this distinction, consider the zebra case (Dretske 1970). In this case, Zula sees that a zebra is in the pen, but intuitively she is unable to

\footnotetext{
${ }^{21}$ Fish's $(2009,2008)$ epistemic view of hallucination is different from Martin's. For the purposes of this paper, however, the differences do not matter.
} 
perceptually discriminate between there being a zebra in the pen from there being a cleverly disguised mule in the pen. Dretske famously denies that Zula is in a position to know that what she sees is not a cleverly disguised mule. According to Pritchard (2012), however, Zula only lacks "discriminating support" for believing that what she sees is not a cleverly disguised mule, because she is unable to perceptually discriminate between them. However, on Pritchard's view, it doesn't follow that Zula thereby cannot know that what she sees is not a cleverly disguised mule. For she has a "wealth of background knowledge" about zoos and "evidence regarding the likelihood" of the zoo-keepers replacing the zebra with a mule painted to just look like a zebra (Pritchard 2012: 79). Once we take into account Zula's total evidence, it turns out that she has better evidence that what she sees is a zebra rather than a cleverly disguised mule: "it is essential that the agent's evidence set incorporates the favoring evidence" that she has to prefer the zebra hypothesis over the cleverly disguised mule hypothesis (ibid 79). This favoring evidence consists in her background inductive and abductive evidence.

We can put the point like this: since Zula knows that the zebra is in the pen, of course her evidence favors the proposition that the zebra is in the pen over the proposition that it's merely a mule disguised to look just like a zebra. However, this fact doesn't entail that Zula can perceptually discriminate between zebras and a range of unlikely alternatives, such as the presence of cleverly disguised mules made to look just like zebras. And so it doesn't entail that Zula has discriminating support for her belief that it's a zebra in the pen. In brief, the view that you cannot know that what you see is not a cleverly disguised mule is ambiguous between two readings:

- Favoring: You cannot know that the zebra isn’t a cleverly disguised mule by way of your favoring support

- Discrimination: You cannot know that the zebra isn't a cleverly disguised mule by way of your discriminatory support.

Pritchard thinks that the favoring reading of the claim is false, but the discrimination reading of the claim is true. Now, here's the worry applied to the case of reflective knowledge of your mental states. You might think that the distinction between favoring and discriminating support applies just as much to knowledge of the mind as it does to knowledge of the world. For example, we can think of introspection or reflection as a kind of "inner perception" or inner perception plus belief, where reflective knowledge of one's occurrent mental state can be grounded in one's introspective discriminatory capacities alone; or that plus one's favoring evidence (e.g., one's background knowledge and purely a priori reasoning).

Proponents of ED can now argue as follows: the cases in which you have reflective knowledge of your rational support (your seeing that $p$-state) for your external world beliefs are cases in which your reflective knowledge is grounded in favoring support rather than discriminating support. Favoring support pulls evidence not just from your current psychological time-slice, such as what you can introspectively discriminate between at that time, but from various historical factors as well, such as your beliefs about how reliable 
your introspection is in terms of generating true beliefs over false beliefs, and how likely it would be that you are suffering a hallucination in which it merely seems to you that you see that $p$. Moreover, it pulls evidence from your stored background knowledge. The application of Pritchard's theory to the case of reflective knowledge for your mental states would end up looking like this (where know $_{\mathrm{RK}}$ is reflective knowledge):

- Favoring*: You can know $_{\mathrm{RK}}$ that your seeing that $p$-state isn't merely a seeming to see that $p$-state by way of your non-empirical favoring support.

- Discrimination*: You cannot know $_{\mathrm{RK}}$ that your seeing that $p$-state isn't merely a seeming to see that $p$-state by way of your introspective discriminatory support.

So, the proponent of ED will say that (P5) of the main argument can be satisfied if we understand 'know, by reflection alone' as reflective knowledge from non-empirical favoring support rather than from introspective discriminating support.

Now, intuitively Discrimination* is correct: you cannot introspectively discriminate between the two states, and thus you cannot reflectively know that they're different by those means. That much is granted by everyone. However, Favoring* is less obvious. Let's distinguish it from the similar claim that:

- Favoring**: You can know that your seeing that $p$-state isn't merely a seeming to see that $p$-state by way of your empirical favoring support.

I concede that Favoring** is far more plausible than Favoring*, because the favoring support you have will be ordinary empirical evidence about the likelihood that you are suffering an introspectively indiscriminable state, merely seeming to see that you have hands, say, rather than actually seeing that you have hands. You already know that this is pretty unlikely, and this background empirical knowledge you have here favors your belief about your mental state.

My argument targets Favoring* instead. There are at least two interrelated problems with Favoring* in connection with the main argument. The first problem registers that proponents of the epistemic conception of introspective indiscriminability need not accept the distinction between favoring and discriminating support at the level of reflective knowledge. For reflective knowledge, it's much harder to see how the distinction applies. Just consider a mundane case of reflective knowledge, such as coming to know, by reflection alone, that you believe that it's raining outside. It's hard to see how this knowledge is achieved without exercising your introspective discriminatory abilities. Intuitively, you selected and discriminated that belief in two ways: from other states of mind, such as hoping that $p$, and from other contents, such as believing that $q$. If you were asked: "how do you know that you believe that $p$ ?", intuitively you would cite the fact that you don't merely, say, hope or wish that $p$. And you might cite the fact that you believe that $p$, rather than some other propositions. This seems to involve the exercise of your introspective discriminatory capacities. To put another way: it doesn't seem like it involves a priori reasoning to the higher-order belief that you believe that $p$. Likewise, you did not appeal to a priori evidence which favors that higher-order belief either. Applied to even a mundane case of reflective 
knowledge, then, it's hard to see how the distinction between favoring and discriminating support is psychologically realistic. ${ }^{22}$

The second problem is that, even with that distinction in play for reflective knowledge, it would still follow that the proponent of ED would need to deny the epistemic conception of introspective indiscriminability, so understood. Now, the proponent of ED could reply by revising the epistemic conception of introspective indiscriminability as follows: 'introspective indiscriminability' is ambiguous between the impossibility of knowing any non-trivial differences between mental states by introspective discriminatory support and the impossibility of reflectively knowing any non-trivial differences between mental states by non-empirical favoring support, such as by a priori reasoning and any a priori favoring evidence. Here's how that might look:

\section{Epistemic Conception DISC:}

For all $\mathrm{S}$, and mental states $m$, a mental state $m_{1}$ is introspectively indiscriminable from $m_{2}$ for $\mathrm{S}$ if and only if $\mathrm{S}$ cannot know, by introspective discriminating support, that $m_{1}$ is not $m_{2}$.

\section{Epistemic Conception $_{\text {FAV: }}$}

For all $\mathrm{S}$, and mental states $m$, a mental state $m_{1}$ is introspectively indiscriminable from $m_{2}$ for $\mathrm{S}$ if and only if $\mathrm{S}$ cannot know, by non-empirical favoring support, that $m_{1}$ is not $m_{2}$.

The proponent of ED could then argue that they don't strictly speaking need to reject the epistemic conception of introspective indiscriminability. For that conception was ambiguous between the two versions above. The proponent of ED could then argue that seeing that $p$ and merely seeming to see that $p$ are introspectively indiscriminable

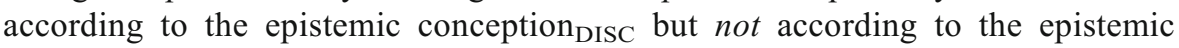
conception $_{\mathrm{FAV}}$. Applied to the main argument, naïve realists and phenomenal character disjunctivists would maintain that perfect ringers for veridical perceptual states are

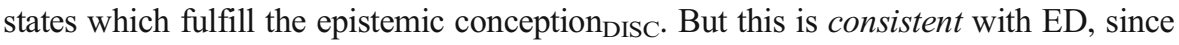
ED maintains that seeing that $p$ is introspectively indiscriminable from merely seeming

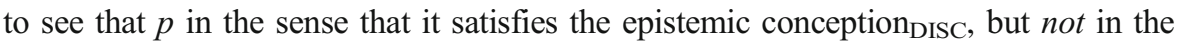

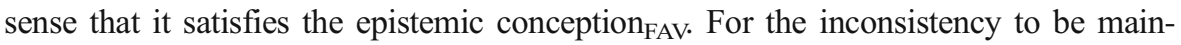
tained, naïve realists and phenomenal character disjunctivists would need to accept that

\footnotetext{
22 Boult (2017) registers is a similar worry, but his focus is on the kind of rational support that your seeing that $p$-state provides to your external world belief that $p$. On his view, it would be ad hoc for the proponent of ED to claim that your seeing that $p$ state provides favoring support but not discriminating support in such cases, since the epistemic support from seeing that $p$ is most naturally thought of as a kind of perceptual discriminatory support. I think his worry applies to the case of reflective knowledge as well: wouldn't it be ad hoc for the proponent of ED to claim your reflective knowledge of your seeing that $p$-state (and that it's not a merely seeming to see that $p$-state) is grounded in purely a priori favoring support as opposed to introspective discriminating support? As I try to make clear in the main text (see also the third problem below), it's hard for us to make any sense of what purely a priori favoring support for your reflective belief that you're in a seeing that $p$-state, as opposed to a merely seeming to see that $p$-state, could be without relying on introspective discriminatory support.
} 


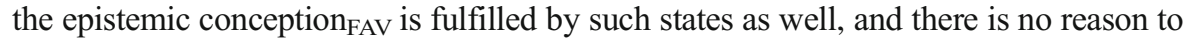
think that they should do that.

The question is whether the more basic distinction between reflective knowledge based in non-empirical favoring support and reflective knowledge based in introspective discriminating support can be sustained. For example, if we cannot find a plausible case where (i) you reflectively know that you see that $p$ rather than that you merely seem to see that $p$ without (ii) relying on introspective discrimination, then the case for the distinction will be substantially undermined.

Let's consider some options. First, you could competently deduce that your mental state is not one of merely seeming to see that $p$ from your reflective knowledge that it is one of seeing that $p$. The problem is that for the a priori deduction to be successfully knowledge-generating, you already need reflective knowledge that your state of mind is one of seeing that $p$. For example, if you begin with your higher-order belief that 'I see that $p$ ' and competently deduce from this 'I don't merely seem to see that $p$ ', this raises the question of how you reflectively know that you see that $p$ in the first place. Intuitively, you need some piece of non-empirical knowledge or evidence to begin the deduction with. Otherwise, it's hard to see why we should count you as a priori knowing the conclusion unless you have a priori knowledge of the premise. And, presumably, you don't reflectively know the premise by way of a priori reasoning either: for what purely a priori argument would support your belief that you see that $p$ ? Presumably, there is no such argument.

Secondly, they could argue that you reflectively know that your state of mind is one of seeing that $p$ by virtue of favoring support by some other purely nonempirical evidence (e.g., not by a priori reasoning). But what purely non-empirical favoring support could you have for that belief? Perhaps there is a memory of track record: the fact that every time you introspected to see whether you were in a factive state of mind in the past, you tended to be in such a mental state. But notice that this simply pushes the challenge back: for those past cases are just as much open to the challenge of how you reflectively know, by non-empirical favoring support, that they occurred as opposed to mere ringers for them. Proponents of ED might reply by positing a reflective factive mental state analogue of seeing that $p$ : inner perceiving that $p .^{23}$ The reply would then be: "you can inner perceive that you see that $p$ ". This would explain how you initially know, by reflection alone, that you see that $p$. The move here is that such inner perception provides you with non-empirical favoring support for your belief that you see that $p$. That such a move is ad hoc notwithstanding, the problem is that the original challenge simply resurfaces here as well. For there will be a ringer for that kind of mental state as well - that is, it can merely seem to you that you inner perceive that you see that $p$ - to which the reply that you can inner perceive that you are not suffering a mere ringer for inner perception will be an intuitively unsatisfying response. Finally, it might be that your non-empirical favoring support for your belief that you see that $p$ is epistemically basic in the sense that it has itself has

\footnotetext{
${ }^{23}$ I chose inner perception, a factive variation of the 'inner sense' model of reflective knowledge of one's mental states, for the sake of simplicity. However, the discussion could in principle proceed with an acquaintance account or a transparency account. See Gertler (2017) for a comprehensive discussion. In general, the discussion can proceed for any way of non-inferentially reflectively knowing which state of mind your in which admits of introspectively indiscriminable ringers.
} 
favoring support. But I think this is subject to worries about introspective indiscriminability as well: why isn't it any more plausible to think that you could know by reflection alone that you see that $p$ only if you can introspectively discriminate such states from merely seeming to see that $p$ ? In general, the problem is that it's hard to see how the proponent of ED will be able to account for why you reflectively know that you see that $p$ rather than merely seem to see that $p$ by way of only non-empirical favoring support. At some stage, an appeal to introspective discrimination seems not only necessary but manifestly advised.

The problem is a very general one for ED. For ED doesn't give us any account of what reflective self-knowledge is, even though it crucially relies on reflective self-knowledge in its account of perceptual knowledge. The epistemic conception of introspective indiscriminability equates the impossibility of knowing by reflection alone that, say, your seeing that $p$-state isn't a mere seeming to see that $p$ state, with the impossibility of introspectively discriminating between them. This creates trouble for ED because, as I argued in $\S 3$, if that view of introspective indiscriminability is true, then ED is false. The proponent of ED might reply, as we have seen, that the epistemic conception is ambiguous between a reading on which you cannot have introspective discriminatory support that one is not the other, and a reading on which you cannot have purely non-empirical favoring support that one is not the other. They could accept the former, but deny the latter. What I have been arguing here is that ED doesn't give us any account of how you get the initial purely non-empirical favoring support that your state of mind is one seeing that $p$. This makes it look ad hoc that you have it. Indeed, this point is perhaps even more evident given that one plausible account of how you could get such reflective knowledge is by way of introspective discrimination. So, proponents of ED need a different story. Since introspective discrimination and a priorireasoning based favoring support is ruled out, we might instead look for some other source of non-empirical favoring support. Inner perception might be one source, such as inner perceiving that you see that $p$. The problem I raised for that kind of reply was that inner perception is a mental state which admits of introspectively indiscriminable ringers as well, and thus the original question of how you reflectively know which state it is without relying on introspective discrimination just resurfaces. In summary, without an account of reflective knowledge of your mental states - and, specifically, of your factive mental states - the reply that such reflective knowledge of your mental states is possible without introspective discrimination should look ad hoc: like a move made only to escape any theoretical burden rather than a principled account of how such reflective self-knowledge is possible. Perhaps such a move can be sustained, but so far we haven't identified any reason to think that is case.

\section{Conclusion}

I've argued that there is considerable pressure on proponents of ED to reject the epistemic conception of introspective indiscriminability. This pressure is grounded in the fact that a commitment of ED is that one can know, by reflection alone, that one sees that $p$, together with plausible views about reflective knowledge. I then argued that 
if the proponent of ED moves to endorse the phenomenal conception of introspective indiscriminability instead of the epistemic conception, then they should reject phenomenal character disjunctivism. In short: ED and phenomenal character disjunctivism wouldn't be a happy couple. I then considered Pritchard's distinction between favoring and discriminating epistemic support, and whether, applied to the case of reflective knowledge, it could furnish proponents of ED with a satisfactory response to the main argument. I then raised two principled challenges for this distinction applied to the case of reflective knowledge, thereby sustaining the main argument.

Open Access This article is distributed under the terms of the Creative Commons Attribution 4.0 International License (http://creativecommons.org/licenses/by/4.0/), which permits unrestricted use, distribution, and reproduction in any medium, provided you give appropriate credit to the original author(s) and the source, provide a link to the Creative Commons license, and indicate if changes were made.

\section{References}

Bonjour, L. (1985). The structure of empirical knowledge. Harvard University Press.

Boult, Cameron (2017). An explanatory challenge for epistemological Disjunctivism. Episteme.

Byrne, Alex \& Logue, Heather (2008). Either/Or. In Adrian Haddock \& Fiona Macpherson (eds.), Disjunctivism: Perception, Action, Knowledge. Oxford University Press 314-19.

Campbell, J. (2002). Reference and Consciousness. Oxford: Oxford University Press.

Cassam, Q. (2007a). The possibility of knowledge. Grazer Philosophische Studien, 74(1), 125-141.

Cassam, Q. (2007b). Ways of knowing. Proceedings of the Aristotelian Society, 107, 339-358.

Dretske, F. (1969). Seeing And Knowing. Chicago: University Of Chicago Press.

Dretske, F. I. (1970). Epistemic Operators. Journal of Philosophy, 67(24), 1007-1023.

Farkas, K. (2006). Indiscriminability and the sameness of appearance. Proceedings of the Aristotelian Society, $106(2), 39-59$.

Fish, William (2008). Disjunctivism, indistinguishability, and the nature of hallucination. In Adrian Haddock \& Fiona Macpherson (eds.), Disjunctivism: Perception, Action, Knowledge. Oxford University Press, pp. $144-167$.

Fish, William (2009). Perception, hallucination, and illusion. Oxford University Press.

Fish, William (2010). Philosophy of perception: A contemporary introduction. Routledge.

French, C. (2012). Does propositional seeing entail propositional knowledge? Theoria, 78(2), 115-127.

French, C. (2013). Perceptual experience and seeing that p. Synthese, 190(10), 1735-1751.

French, C. (2016). The formulation of epistemological Disjunctivism. Philosophy and Phenomenological Research, 92(1), 86-104.

Gertler, Brie (2017) "Self-knowledge”, The Stanford Encyclopedia of Philosophy (Fall 2017 Edition), Edward N. Zalta (ed.), URL $=<$ https://plato.stanford.edu/archives/fall2017/entries/self-knowledge/>. Access date: January 10, 2017.

Ghijsen, H. (2015). The basis problem for epistemological Disjunctivism revisited. Erkenntnis, 80(6), $1147-1156$.

Gisborne, N. (2010). The Event Structure of Perception Verbs. Oxford: Oxford University Press.

Goldberg, S. (2016). Comments on Pritchard's epistemological Disjunctivism. Journal of Philosophical Research, 41, 183-191.

Greenough, P. (2012). Discrimination and self-knowledge. In D. Smithies \& D. Stoljar (Eds.), Introspection and consciousness. Oxford University Press.

Haddock, Adrian \& Macpherson, Fiona (2008). Introduction: Varieties of disjunctivism. In Adrian Haddock \& Fiona Macpherson (eds.), Disjunctivism: Perception, Action, Knowledge. Oxford University Press.

Kraft, T. (2015). Epistemological Disjunctivism's genuine access problem. Theoria, 81(4), 311-332.

Littlejohn, C. (2016). Pritchard's reasons. Journal of Philosophical Research, 41, 201-219.

Madison, B. J. C. (2014). Epistemological Disjunctivism and the new evil demon. Acta Analytica, 29(1), 61-70. 
Martin, M. G. F. (2002). The Transparency of Experience. Mind \& Language, 17, 376-425. https://doi. org/10.1111/1468-0017.00205.

Martin, M. G. F. (2004). The limits of self-awareness. Philosophical Studies, 120(1-3), 37-89.

Martin, M. G. F. (2006). On Being Alienated. In T. S. Gendler \& J. Hawthorne (Eds.), Perceptual Experience. Oxford University Press.

Martin, M. G. F. (2007). Perception. The Oxford Handbook of Contemporary Philosophy. Oxford: Oxford University Press. http:/www.oxfordhandbooks.com/view/10.1093/oxfordhb/9780199234769.001.0001 /oxfordhb-9780199234769-e-24. Access date: January 10, 2017.

McDowell, J. (1983). Criteria, Defeasibility, and Knowledge. Proceedings of the British Academy (Volume 68: 1982, pp. 455-479). Oxford: Oxford University Press.

McDowell, J. (1986). Singular Thought and the Extent of 'Inner Space'. In John McDowell \& Philip Pettit (Eds.), Subject, Thought, and Context. Oxford: Clarendon Press.

McDowell, J. (1995). Knowledge and the internal. Philosophy and Phenomenological Research, 55(4), $877-893$.

McDowell, J. (2002). Replies. In Reading McDowell: On Mind and World, (Ed.) N. Smith. Routledge: London and New York.

Pritchard, D. (2010). Relevant Alternatives, Perceptual Knowledge and Discrimination. Noûs, 44(2), 245-268.

Pritchard, D. (2011). Epistemological Disjunctivism and the basis problem. Philosophical Issues, 21(1), 434-455.

Pritchard, D. (2012). Epistemological Disjunctivism. Oxford: Oxford University Press.

Pritchard, D. (2015). Epistemic Angst: Radical skepticism and the Groundlessness of our Believing. Princeton: Princeton University Press.

Pritchard, D. (2016). Epistemic Angst. Philosophy and Phenomenological Research, 96, 70-90. https://doi. org/10.1111/phpr.12280.

Ranalli, C. (2014). Luck, Propositional Perception, and the Entailment Thesis. Synthese 191(6):1223-1247.

Siegel, Susanna (2008) The epistemic conception of hallucination. In Adrian Haddock \& Fiona Macpherson (eds.), Disjunctivism: Perception, Action and Knowledge. Oxford University Press 205-224.

Siegel, Susanna (2010). The contents of visual experience. Oxford University Press.

Stroud, Barry (2011). Seeing what is so. In Johannes Roessler, Hemdat Lerman \& Naomi Eilan (eds.), Perception, causation, and objectivity. Oxford University Press.

Turri, J. (2010). Does perceiving entail knowing? Theoria, 76(3), 197-206.

Tye, M. (2002). Representationalism and the Transparency of Experience. Noûs, 36(1), 137-151.

Williamson, T. (2000). Knowledge and its Limits. Oxford: Oxford University Press.

Williamson, T. (2013). Identity and Discrimination. Hoboken: Wiley-Blackwell.

Zalabardo, J. (2015). Epistemic Disjunctivism and the Evidential Problem. Analysis, 75(4), 615-627. 